\title{
SIMPLE INFLAMMATORY PARAURETHRAL CYST: A CASE REPORT
}

Shankar B. Burute ${ }^{1}$, Karuna Ratwani², Tullika Singh ${ }^{3}$

\section{HOW TO CITE THIS ARTICLE:}

Shankar B. Burute, Karuna Ratwani, Tullika Singh. "Simple Inflammatory Paraurethral Cyst: A Case Report". Journal of Evolution of Medical and Dental Sciences 2014; Vol. 3, Issue 11, March 17; Page: 2757-2759, DOI: $10.14260 /$ jemds/2014/2205

INTRODUCTION: Paraurethral cyst is an uncommon and may be congenital or acquired. Presenting symptoms include a palpable or visible mass, pain, dyspareunia, dysuria, a distorted voiding stream, and a vaginal discharge. Paraurethral cyst affects $1 \%$ to $6 \%$ of the female population between 20 and 60 years of age. CASE REPORT: A 23 year old patient came with complaints of dysuria, dyspareunia and swelling in the vaginal region since 6 months, size being gradually increasing in size to the present size of $4 \mathrm{x} 4 \mathrm{cms}$ giving a picture of paraurethral cyst. Ultrasonography was suggestive of a simple cyst and rest all investigations were in normal limits. During surgery, a unilocular cyst adherent to the urethral wall on the right side was appreciated. DISCUSSION: In this case, it was typically diagnosed upon physical examination, although ultrasound was used to confirm. We conclude that paraurethral cysts in adults are benign lesions that respond well to simple marsupialization, with no recurrence. The major risk factor in the present patients was pregnancy and vaginal delivery, but cysts can occur in nulliparous women.

KEYWORDS: Paraurethral cyst, Ultrasonography.

INTRODUCTION: The paraurethral cyst is uncommon and may be either congenital or acquired. Presenting symptoms include a palpable or visible mass, pain, dyspareunia, dysuria, a distorted voiding stream, and a vaginal discharge ${ }^{1}$.

Paraurethral cysts may be totally asymptomatic and discovered during routine pelvic examination. Paraurethral cyst affects $1 \%$ to $6 \%$ of the female population between 20 and 60 years of age. Urethral diverticula account for approximately $80 \%$ of paraurethral cyst-like lesions.2, 3 Paraurethral cysts are considerably less frequent. Because of their usually asymptomatic character, paraurethral cysts are rarely diagnosed and treated, and reports available in databases are relatively scarce. However, the presence of cysts may cause recurrent genitourinary symptoms. Symptomatic cysts are an indication for surgical treatment.

CASE REPORT: A 23 year old patient came with complaints of dysuria, dyspareunia and swelling in the vaginal region since 6 months, size being gradually increasing in size to the present size of $4 \times 4$ cms. Ultrasonography was suggestive of a simple cyst and rest all investigations were in normal limits. During surgery, a unilocular cyst adherent to the urethral wall on the right side was appreciated. On compressing the cyst a yellow serous discharge drained from the urethra which was not possible earlier due to tremendous pain on previous such attempts without anesthesia. Cyst was removed \& sent for histopathology. Rent in urethra was sutured with vicryl 3-0 and the dead space obliterated with the same. Patient was catheterized and catheter kept for 7 days. Patient was discharged after 7 days and was asymptomatic at follow up. Histopathological report of the cyst was confirmed it as a simple inflammatory cyst of a paraurethral region. 
DISCUSSION: Paraurethral cysts in women are classified primarily as acquired or congenital, although a clear distinction often is difficult. Congenital paraurethral cysts arise from the various embryological components and vestigial remnants of the vagina and the female urethra ${ }^{4}$. Acquired inclusion cysts of the surface epithelium have been reported as the most common cystic lesion of the vagina $^{5}$, often thought to be secondary to the trauma of childbirth or caused by iatrogenic surgical trauma, e.g. episiotomy. Microscopically, the cysts usually are lined by stratified squamous epithelium and may contain caseous or purulent material. ${ }^{4}$

The cyst usually presents itself as a soft, oval and mobile mass. Sometimes the tension of the cystic wall suggests the presence of a solid tumor. Therefore, differential diagnosis of paraurethral tumor-like lesions should take into consideration numerous cystic and solid structures, such as: urethral diverticula, ectopic ureterocele prolapse, leiomyomas, squamous cell carcinomas, neurofibromas, etc. ${ }^{4,6}$
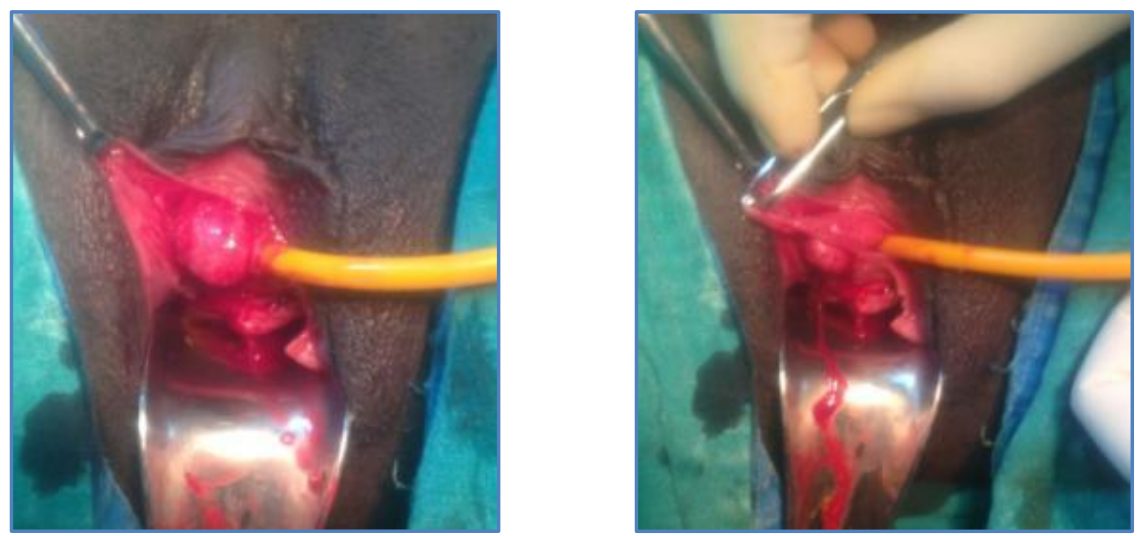

Figure 1 \& 2 Shows $4 \times 4$ cms Paraurethral Cyst

The exact etiology of paraurethral cysts is not known. Exposure to maternal estrogen has been reported as a possible cause for development of paraurethral cyst but there is no documented report of maternal exposure in any of the reported cases in the English literature. ${ }^{7}$ For persistent cysts or cases where intervention is required, drainage of the cysts by aspiration, unroofing and marsupialization have all been tried with success.

Skene's ducts are the largest of 30 paraurethral ducts that empty into the female urethra. Occasionally, duct obstruction may lead to a periurethral cyst which presents as an interlabial mass. A normal vaginal introitus can be seen below the cyst. Moreover, a paraurethral cyst contains a milky-fluid if aspirated. The paraurethral glands and ducts that empty into the female urethra are rudimentary homologues of the prostate. Paraurethral glands secrete a mucus-like substance that provides lubrication to the urethral meatus, particularly in response to sexual stimulation. ${ }^{8}$

Paraurethral gland cysts are rare congenital abnormality which present as an interlabial cystic mass in new-born girls. The true incidence of this anomaly is not known. The reported incidence varies from 1 in 2074 to 1 in 7242 female births ${ }^{9}$. Usually physical examination of external genitalia is diagnostic but ultrasound can be used to facilitate in narrowing down the differentials.

CONCLUSION: The incidence of paraurethral cysts may be higher than reported. It is typically diagnosed upon physical examination, although ultrasound may be used to confirm. We conclude that 
paraurethral cysts in adults are benign lesions that respond well to simple marsupialization, with no recurrence. The major risk factor in the present patients was pregnancy and vaginal delivery, but cysts can occur in nulliparous women.

\section{REFERENCES:}

1. Stovall TG, Muram D, Long DM. Paraurethral cyst as an unusual cause of acute urinary retention. J Reprod Med 1989; 34:423.

2. Blaivas JG, Flisser AJ, Bleustein CB, Panagopoulos G. Periurethral masses: etiology and diagnosis in a large series of women. Obstet Gynecol 2004; 103: 842-847.

3. Cross JJ, Fynes M, Berman L, Perera D. Prevalence of cystic paraurethral structures in asymptomatic women at endovaginal and perineal sonography. Clin Radiol 2001; 56:575-578.

4. Das SP. Paraurethral cysts in women. J Uro 1981; 126:41.

5. Deppisch LM. Cysts of the vagina: Classification and clinical correlations. Obst Gynec 1975; 45: 632.

6. Witherington R, Smith AM. Management of prolapsed ureterocele: past and present. J Urol 1979; 121: 813-815.

7. Wright JE. Paraurethral (Skene's Duct) Cysts in the Newborn Resolve Spontaneously. Pediatric Surgery International 1996; 11: 191-192.

8. Merlob P, Bahari C, Liban E, et al. Cysts of the Female External Genitalia in the Newborn Infant. American Journal of Obstetrics \& Gynecology 1978; 132: 607-610.

9. Fujimoto T, Suwa T, Ishii N, et al. Paraurethral Cyst in Female Newborn: Is Surgery Always Advocated? Journal of Pediatric Surgery 2007; 42(2):400-403.

\section{AUTHORS:}

1. Shankar B. Burute

2. Karuna Ratwani

3. Tullika Singh

\section{PARTICULARS OF CONTRIBUTORS:}

1. Associate Professor, Department of Obstetrics and Gynaecology, Dr. D. Y. Patil Medical College, Pune.

2. Resident, Department of Obstetrics and Gynaecology, Dr. D. Y. Patil Medical College, Pune.

3. Resident, Department of Obstetrics and Gynaecology, Dr. D. Y. Patil Medical College, Pune.

\section{NAME ADDRESS EMAIL ID OF THE CORRESPONDING AUTHOR:}

Dr. Shankar B. Burute, Flat No. 106, Building No. 38, Prateek Nagar, Yerwada, Pune - 411006.

E-mail: sbburute@gmail.com

Date of Submission: 05/02/2014.

Date of Peer Review: 06/02/2014.

Date of Acceptance: 19/02/2014.

Date of Publishing: 05/03/2014. 